\title{
SOBRE CONSTITUCIONES Y REVOLUCIONES BURGUESAS
}

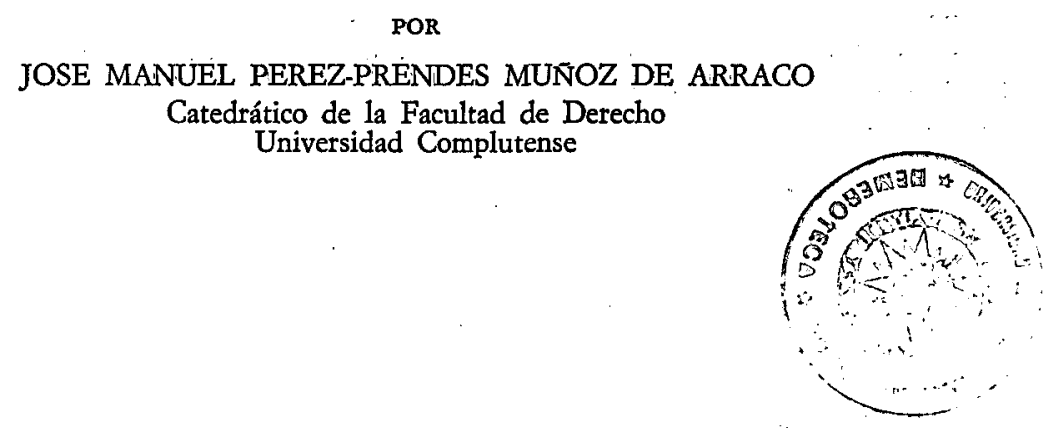

La Constitución de 1837 (que se presenta como versión reducida y revisada de la de 1812, pero que es mucho más trascendente que eso) encierra una significación muy especial en el desartollo del constitucionalismo español. Cuando, en 1978 (y frente a la superficial pero repetida visión que, sólo contabilizando textos, considera comparable nuestro constitucionalismo a los esfuerzos de Penélope), propuse un modelo de comprensión de los significados más profundos de ese desenvolvimiento, modelo basado en la sucesión imbricada de tres momentos fundamentales ${ }^{1}$, partía precisamente de una frase que Adolfo Posada, uno de nuestros mejores expositores de Derecho constitucional, dedicó a la carta de 1837, diciendo que a partir de ella «las acciones y reacciones políticas tendrán como supuesto una Constitución» ${ }^{2}$.

Se abre, pues, en ese año el período que denomino de «consolidación constitucional», frase cuya significación conserva signos de vitalidad explicativa, si bien se van lentamente atenuando, hasta que, llegado el sexenio revolucionario que corre de 1868 a 1874 , nos encontramos con que ya se ha sobrepuesto a esa preocupación otra dimensión de tensiones nacionales que va mucho más allá de la convicción, propia del momento anterior (el de consolidación) de que se podía lograr un texto jurídico en el que las pasiones y razones enfrentadas entre los españoles pudiesen hallar un espacio de acuerdos.

Como en toda Constitución, es preciso distinguir (no aislar) en la de 1837 el plano de las fuerzas sociales que la configuran, esgrimen o combaten, de aquel otro relativo a los aspectos de técnica jurídica con la que se la redacta.

Respecto del primero, es ya un tópico apelar a la «revolución burguesa», sin más, cuando en ciertas síntesis histórico-jurídicas que se publican en nuestros días se afronta la historia de nuestro constitucionalismo y concretamente se toca la Constitución que nos ocupa. Así, este concepto, uno de los más

1 J. M. Pérez-Prendes, Curso de Historia del Derecho español, Madrid, 1978 capítulo XXVII, págs. 769 y sigs., así como «Continuidad y discontinuidad en la Constitución de 1876», en esta misma Revista, 8 (Invierno 1981).

${ }_{2}$ A. Posada, Tratado de Derecho político, vol. II, Derecho constitucional comparado de los principales Estados de Europa y América, Madrid, 1935, pág. 285. 
ricos, pero también difícil elemento a descubrir en el curso de la historia, corre cada vez más el riesgo de convertirse entre noostros en una especie de gran caja cerrada que se coloca ante los ojos de aquellos a quienes va dirigida la labor de tales historiadores, añadiendo que por un lado entra el «Antiguo Régimen» y por otro sale el «Estado de Derecho». Naturalmente, el espectador ignora (y quizá también quien se lo cuenta) qué es lo que ocurrió dentro de la caja. Mucho tendrán todavía que trabajar los historiadores de la economía para que podamos establecerlo con detalle, pero hoy por hoy ya vamos sabiendo algunas cosas que pueden ayudar a ello. Así, la consideración general (aun corregida por excepciones), señalada por Simón Segura ${ }^{3}$, respecto de que la conducta del capitalista nacido de la desamortización «careció del rasgo fundamental del espíritu empresarial» y más que reinvertir beneficios prefirió repetir los esquemas de la aristocracia, cosa en cierto modo ya prevista en 1625 por Fernández de Navarrete, cuando se quejaba de que los mayorazgos sólo servían para «acaballerar la gente plebeya, vulgar y mecánica». Sabemos, correlativamente, que incluso mucho después, ya en la Restauración, la Banca privada, o conjunto de sociedades crediticias (aparte el Banco de España), desarrollado desde 1856 bajo los signos de la tendencia a la concentración, la baja densidad y la desproporción con el de España ${ }^{4}$, sigue registrando una preferencia a la «inmovilización en activos reales, o en inversiones de dudosa rentabilidad», frente a la práctica y desarrollo del crédito indusctrial, como ha señalado Tedde de Lorca, quien recuerda que «es de destacar las crecientes cifras de los depósitos a la vista de los bancos, en los mismos años en que su actividad crediticia menguaba»; y también que llegamos a 1900, con una situación de «escaso crédito concedido a las actividades industriales» ${ }^{5}$. ¿No se podrá aquí, usando del lenguaje de Pierre Vilar, pensar que esos compradores de bienes «nacionales» primero, y esos depósitos bancarios después, están más cerca de ser, o son en definitiva, unos poseyentes inactivos, diferenciables en rigor de los poseyentes activos, es decir, los empresarios o arrendatarios capitalistas que asumen el riesgo de buscar el beneficio empresarial? Más adelante veremos la posibilidad de algunos pactos tácitos que explicarían esa conducta, con una burguesía liberal tratando de diluirse en la aristocracia. Desde luego que aquí yo sólo me limito a preguntar, pero en cualquier caso, como la prudencia de Nadal señala, el modelo español es muy complejo y resulta todavía atrevimiento una formulación global. Cosa que advierte al reflexionar sobre las agudas sugerencias de Nicolás Sánchez-Albornoz, cuando ambos se enfrentan con la indagación de las causas que frenaron en España la revolución agraria, alejando así la posibilidad de alcanzar la revolución industrial.

${ }^{3}$ F. Simón Segura, La desamortización española en el siglo XIX, Madrid, 1973, páginas 296-298.

${ }^{4} \mathrm{G}$. Tortella Casares, Los orígenes del capitalismo en España, Madrid, 1973, págs. 326 y sigs.

P. Tedde de Lorca, «La Banca privada española durante la Restauración (1874-1914)», en La Banca española en la Restauración, I, Política y finanzas, págs. 449 y sigs.

' J. Nadal, El fracaso de la Revolución industrial en España, 1814-1913, Barcelona, 19?5, págs. 244-245; P. Vilar, Iniciación al vocabulario del análisis bistórico, Barcelona, 1980, pág. 140. 
Estos mínimos préstamos que a modo de ejemplos acabamos de tomar de algunos historiadorés dè la economía, cuyá competencia no es tema discutible, nos recuerdan varios riesgos importantes. Uno de ellos, ló peligroso que puede resultar el intentar ponerle año concreto a la consumación del tránsito a sociedad capitalista en España, y comó ese albur es frecuentemente sufrido en las grandes síntesis generales o histórico-jurídicas; hàce falta insistir siempre en su recuerdo. Además, la necesidad de contemplar la cuestión de ese tránsito en España, como algo más que un proceso claro o sencillo, la necesidad de que descompongamos sus posibilidades y fasés y debatamos sobre ellas. Si, como ha señalado Hernández Montalbán, el propio Pierre Vilar vacila en' el tema de la revolución burguesa en España ${ }^{7}$; si Gonzalo Anes ha subrayado cómo el «complejo revolucionario» que se inicia con los motines de 1766 para cambiar el Antiguo Régimen sufrió una inserción en el XIX en «circunstancias históricas distintas a aquellas en que se había planteado la necesidad de una ley agraria, circunstancias que de hecho permitieron realizar làs reformas en beneficio de los privilegiados» ${ }^{8}$, ¿no es demasiado dogmático y superficial pergeñar deprisa y corriendo en un «Manual» de historia jurídica una definición escolástica de «revolución burguesa» para luego seguirla utilizando como una categoría mineralizada que se pone en este o el otro lugar del discurso del historiador del derecho y dando por sobreentendido al lector con dos palabras una transformación que algunos profesorès están todavía muy lejos de ser capaces de pormenorizar?

Pierre Vilar ha señalado con claridad el rasgo de «precocidad» que es necesario para que estos movimientos logren sus objetivos. ${ }^{9}$. Pero la idea de precocidad supone insistir en algo que ya había dicho otra vez ${ }^{10}$ : las revoluciones burguesas tienen una historia. Esa historia y ese plural denotan que se dilatan y diversifican, pudiendo apreciarse vías diversas y mezclas entre muchos acontecimientos para que la resultante final ofrezca, a lo largo de un desenvolvimiento complejo, una mixtura diversificada según las épocas y los lugares. Esencialmente, y prescindiendo de fantasmagorías cọmo las analizadas. por Fontana ${ }^{11}$, la idea de «revolución burguesa» en cuanto instrumento de análisis histórico hace referencia a cómo para poder actuar conforme a su naturaleza, que le lleva a crear «fuerzas productivas más abundantes y más grandiosas que todas las generaciones pasadas juntas», «no puede existir sin revolucionar incesantemente los instrumentos de producción y, por consiguiente, las relaciones de producción y con ello todas las relaciones sociales» ${ }^{12}$. Al

7 En el volumen colectivo Estudios sobre la revolución burguesa en España, Madrid, 1979, pág. 116, nota 2.

${ }^{8}$ Sucesivamente me apoyo en su El Antiguo Régimen. Los Borbones, Madrid, 1975 , pág. 382 del vol. IV de la Historia de España Alfaguara, y en «Tensiones sociales en la España del Antiguo Régimen», en el vol. colectivo Clases y conflictos sociales en la Historia, Madrid, 1977, pág. 113.

${ }^{9}$ Cfr. op. cit. supra, nota 6 , pág. 257.

${ }^{10}$ En El feudalismo, Madrid, 1972, pág. 69.

$1 \mathrm{~J}$. Fontana, «Sobre revoluciones burguesas y autos de fe», en Mientras tanto, 1 (1979); «Transformaciones agrarias y crecimiento económico en la España contemporánea», en Cambio económico y actitudes políticas en la España del siglo. XIX, Barcelona, 1973, págs. 147 y sigs.; esta última obra para lo que se dice más adelante.

${ }_{12}$ Manifiesto comunista, ed. en Marx y Engels, Obras escogidas, Madrid, 1975, vol. I, págs. 26 y 25 , respectivamente. 
rebelarse, como recuerda Engels, las «fuerzas productivas representadas por la burguesía» contra «el régimen de producción representado por los terratenientes feudales y los maestros de los gremios» ${ }^{13}$, fue necesario luchar por una libertad económica (de empresa, de métodos productivos, de intercambios), una igualdad jurídica y una libertad politica, conceptos nada lineales y sí muy complejos, que son objeto de atención por «todos los que tienen interés en los intercambios multiplicados, en la propiedad sin trabas, a saber todo tipo de comerciantes, agricultores ricos o acomodados, incitados por la coyuntura económica a saltarse los reglamentos y los privilegios, extranjeros o feudales. La toma del poder por los representantes de estas capas sociales crea las condiciones para la aparición del capitalismo» ${ }^{14}$.

Ahora bien, si con esos razonamientos queda claro que puede haber, sin burguesías, movimientos revolucionarios que hagan posibles los fines de una revolución burguesa, o mejor aún, que creen las condiciones para que aquellas clases se constituyan y fortalezcan, logrando luego por su propia obra sus objetivos revolucionarios, no es menos perceptible que las heterogeneidades y variables que caben en esas sacudidas precoces son inmensas y muchas veces sin conciencia o sin coincidencia con esos efectos finales, a los que pueden contradecir o afectar gravemente. No es un capricho de Marx que exista una «vía prusiana» al capitalismo basada en unas actitudes de pacto y compromiso entre sectores beneficiarios de que algo cambie para poder conservar ellos mucho. No deja de ser cosa plena de lucidez la distinción de Fontana entre reformas agrarias liberales y revolucionarias, según esté integrada o no respectivamente, en ellas, la posibilidad de una transacción establecida entre quienes se aprestan a ser sus beneficiarios. Y digo con toda consciencia que ésta es una interpretación inteligente, sabiendo que hay buscadores de notoriedad que inútilmente se enfrentan con ella. Así las cosas, parece mucho más flexible y ajustado a la necesaria carencia de pre-juicios que debe presidir cualquier intento de investigación histórica, apelar a la categoría de «complejo revolucionario» utilizada ya, como antes se dijo, por el profesor Gonzalo Anes, e insertar en ella, entre las fuerzas que la integran, la dosis, alternancia o predominio de las diferentes vías apreciables, ya que reducir todo a una sola puede desdibujar la gran suma de contradicciones que son factibles de darse cita en el marco mayor de un «complejo revolucionario» y desde luego se dan entre nosotros, siendo muy apreciables, al menos en el espacio que transcurre flanqueado por acontecimientos como la cadena de motines de marzo y abril de 1766 y en 1837 (cuando fracasa la «expedición real» de los carlistas) o en 1845 cuando se retorna hacia las posturas establecidas en el Estatuto Real de 1834.

A mi entender, la Constitución de 1837 cobra, vista así, una especial profundidad. El complejo revolucionario (si se acepta hablar así) al que asistimos en España desde 1766 habría tenido como fase inicial el tiempo que hemos llamado de «contradicciones radicales» con el Antiguo Régimen, y sólo desde 1868 se podría hablar con propiedad de una revolución burguesa en plenitud $y$ no en balbuceos (por precisos que sean los segundos para alcanzar la pri-

${ }^{13}$ «Ludwig Feuerbach y el fin de la filosofía clásica alemana», ed. en Obras, cit., volumen II, pág. 416.

${ }^{14}$ P. Vilar, op. cit. supra, nota 6, págs. 256-257; cfr. también págs. 208 y sigs. 
mera) balbuceos que sí aparecen en cambio en 1837, mientras que antes son los heterogéneos colectivos señalados por Pierre Vilar los que protagonizan sólo una preparación de caminos. La alianza tácita entre la aristocracia terrateniente y la burguesía «acaballerada» liberal (cuyos ancestros ya buscaron su confusión, o mejor su transustanciación, en la primera, usando en otro tiempo de mayorazgos y preeminencias concejiles) presenta un claro síntoma en el «estamento de próceres» del Estatuto Real, pero hasta que en 1837 se advierta la inviabilidad de la solución militar carlista, aún acariciará la primera algún sueño de ruptura con la segunda. Las propiedades de los que han quedado fuera del pacto, Iglesia y municipios, serán su botín. Nota significativa en este sentido será el hecho de las agitaciones que van a sacudir todo el período de vigencia de ésta Constitución, los ocho años que median entre 1837 y 1845; el tema que resultará el eje de esas convulsiones será la Ley de Ayuntamientos de 1840, provocando el fin de la regencia de la reina viuda María Cristina. Tampoco durará sino apenas un trienio la regencia del general Espartero, y la prácticamente dictadura del Partido Moderado, que le sustituye, facilitará la redacción de un nuevo texto constitucional, el de 1845, de claros visos de éxito explotable por los pactistas, sin Cortes Constituyentes, con un Senado de nombramiento real, ilimitado y vitalicio, con una función judicial no configurada como poder, sin garantías, previstas en el texto de 1837 (art. 27), para el caso de que el Monarca no reúna las Cortes, con diputados de mandato quinquenal, frente al trienal de las previstas (art. 25) en 1837, etcétera. En conjunto, y es fácil aumentar los ejemplos, una concepción bien claramente al servicio de la consolidación de los intereses ya soldados en 1837, tanto en la parte dogmática como en la orgánica, pero mucho más perceptibles en ésta.

Efectivamente, es comparando los textos de 1837 y 1845 , y no los de 1812 y 1837 (como corrientemente suele hacerse) como mejor se advierte el discreto, pero firme esfuerzo de 1837, en desviar. la reforma revolucionaria de lo prescrito en 1812. Cierto que se ha hablado de tetrocesos muchas veces, al aludir a 1837, pero volviendo ahora a la correlación que recordábamos al principio de estas páginas entre los dos planos mencionados, uno, el de las fuerzas sociales implicadas, y otro, el relativo a los aspectos de técnica jurídica que se aplica en la redacción, conviene preguntarse por el verdadero sentido de esos retrocesos. Así, no deja de sentirse la impresión de que unas veces se ha forzado la redacción al máximo para lograr objetivos que todavía se consideraban demasiado revolucionarios por amplios sectores, implicados, no obstante, también por ese pacto tácito en el «complejo revolucionario»; y en otras ocasiones, en cambio, se ha cedido ante ellos. Un ejemplo que a mí me parece claro es lo ocurrido con el tema de la soberanía nacional, que se resuelve bellamente en conformidad con la burguesía liberal. La Constitución de 1812, en su artículo $3 .^{\circ}$, afirma que «la soberanía reside esencialmente en la nación», pero en la de 1837 no hay que buscar un artículo paralelo, que no existe. ¿Se puede deducir de aquí, como tantas veces se dice, que el principio resulta entonces atenuado? Entiendo que no, ni formal, ni realmente, ni de ningún modo, pues ya en el Dictamen de la Comisión de Constitución de 30 noviembre 1836 aparece claro que ésta entendía su labor como reforma de la gaditana, y, además, en el preámbulo de la Constitución misma se hace constar que, «siendo 
voluntad de la Nación revisar, en uso de su soberanía, la Constitución, etc.». Todo lo cual indica que se entendía establecido tal axioma desde Cádiz, y lo que se hace ahora es justamente aplicarlo, en forma natural, sin que sea preciso reafirmar lo que se sabe vigente. Dirán quienes tengan una visión superficial que quizá hubiese sido buena la rutina de repetir el principio en el articulado, pero hay que tener en cuenta dos cosas; primera, que una reiteración expresa hubiese sido contraproducente para los sectores «moderados»; segunda que, en rigor, implicaba una mayor vigencia darlo por admitido y precisamente para centrar sobre él toda la existencia misma de la Constitución. Claramente se expresan en este sentido y con estos argumentos los redactores en la Exposición que presenta el proyecto, donde rechazan expresamente la conveniencia de incluir el «gran principio de la soberanía nacional... único origen legítimo de todas las Constituciones de los pueblos», por sí sólo en un artícu$\mathrm{lo}^{15}$. Estas consideraciones debieron pesar en el ánimo de Posada, cuando afirmó sin más: «Ambas afirman la soberanía nacional» ${ }^{16}$. Basta, en cualquier caso, observar la suerte que corre esta cuestión cuando, en 1845, la Constitución ya no es obra de la Nación, como en 1837, sino del Rey, a quien auxilian, claramente subordinados, unos súbditos que se congregan no en Cortes Constituyentes, sino «actualmente reunidas» y todo ello en una clara afirmación de continuismo con «los antiguos fueros y libertades de éstos reinos». Demasiado elíptico resultaba, en cambio, el reformar la Constitución, cuestión de la que no se hace mérito en la de 1837, en claro contraste con lo que ocurre en la de 1812 (título X). Podría decirse, y alguien ha dicho, que así se entendía reformable el texto por el mismo sistema legislativo común y ordinario. Sin embargo, no es menos cierto que si, como ya sabemos, se afirma al comienzo y en la Exposición que la Constitución es revisada por la Nación en uso de su soberanía, resulta incongruente que además puedan revisarla otras instancias que no poseen tal rango. De todos modos, o los redactores pensaron que con el silencio bastaba para que se llegase a esa conclusión, o las habilidades técnicas estuvieron aquí al servicio de la otra banda de los beneficiarios, los «moderados» y «doctrinarios» que lograrían su hora de audiencia con el texto de 1845, lo mismo que lo habían conseguido en 1834 con el Estatuto Real.

Clara voluntad sistematizadora mostró la Exposición en lo concerniente a los «derechos políticos» y las «garantías de su seguridad individual» reconocidos a los españoles y «esparcidos por diferentes capítulos de la Constitución (de 1812)». Pero esta primera sistematización que ofrece nuestro constitucionalismo (arts. $2 .^{\circ}-10$ ) se resiente de excesiva preocupación por las inquietudes de la burguesía de su época, en lugar de plantearse una visión teórica que hubiese podido resultar menos vulnerable al paso del tiempo. Así, la preocupación por la libertad de imprenta, colocada al principio, y de la que dirá la Exposición que se puso en tal lugar «como el primero y más interesante de todos los derechos y el más eficaz y seguro para la conservación y defensa de

${ }^{15}$ Ed. en D. Sevilla Andrés, Constituciones y otras leyes y proyectos políticos de España, Madrid, 1969, vol. I, págs. 317 y sigs. para la «Exposición» y 307 y sigs. para el «Dictamen» que anteriormente hemos citado.

${ }_{16}$ A. Posada, op. cit. supra, nota 2, pág. 286. 
los restantes». El cuadro se completa con el derecho de petición, el reconocimiento del mérito y capacidad para la provisión de los cargos públicos, los de inviolabilidad domiciliaria y de la propiedad, el de seguridad de las personas $y$, en fin, uniformidad de legislación y unidad de fuero. Poco sobre la dignidad humana y nada sobre el respeto a la vida. Evidentemente, era todavía muy largo el camino a recorrer, como quizá lo es todavía hoy, para que se comenzase a vislumbrar que en esa cuestión, aparentemente tan sólida que, por sabida se podía dar por callada, iban más tarde a cruzarse las sombras amenazantes de la tortura, la eutanasia, el aborto o el servicio militar obligatorio, $\mathrm{y}$, desde luego, a la hora de elegir una pena que «no se impondrá jamás» (artículo 10), no se pensaba en la de muerte, sino en la confiscación de bienes y en la privación de la propiedad. Pero de la propiedad de aristócratas y burgueses, y no de los excluidos de un acuerdo sin palabras, pero con hechos, la propiedad de la Iglesia y los municipios. No es posible ni necesario aquí otra cosa que el recuerdo de las decisiones desamortizadoras contemporáneas a la Constitución de 1837 a costa de los descabalgados del acuerdo y, por supuesto, de las masas campesinas.

Este texto, con su bicameralismo, y su enjuta regulación de temas como la constitución, actuación y facultades de las Cortes (arts. 12-43), los ministros (arts. 61-62), el poder judicial (arts. 63-67) y los Ayuntamientos (arts. 70-71), etcétera, es algo más, mucho más que una reducción formal del texto gaditano. No se trata de tamaños. Se ha censurado mucho la extensión, que los juristas siempre han creído desmesurada, de los 384 artículos del texto de 1812, pero ¿no era quizá imprescindible, en momentos como los que entonces se vivían, luchando por primera vez con fuerza contra el Antiguo Régimen, fiar lo menos posible al desarrollo constitucional, cuando, como se vio, ni la misma Constitución estaba segura? Cierto que técnicamente tal extensión es un dislate, pero sus redactores también sabían que políticamente no existía otro camino, y quizá ni aún ese, para intentar consolidar su obra. Lo que sí está claro es que ese esquema revolucionario de Cádiz se ha convertido en 1837 en otra cosa, se ha convertido en una vía de compromiso al capitalismo, entre aristocracia y burguesía, acuerdo cuyas claves de cierre son los 77 artículos y dos disposiciones adicionales de la Constitución de 1837. 